\title{
Enhanced musical rhythmic perception in Turkish early and late learners of German
}

\section{Paula Roncaglia-Denissen ${ }^{1 *}$, Maren Schmidt-Kassow ${ }^{2}$, Angela Heine $^{3}$, Peter Vuust $^{4,5}$ and Sonja A. Kotz ${ }^{1,6}$}

${ }^{1}$ Department of Neuropsychology, Max Planck Institute for Human Cognitive and Brain Sciences, Leipzig, Germany

2 Institute of Medical Psychology, Goethe University Frankfurt, Frankfurt am Main, Germany

${ }^{3}$ Department of Psychology, Freie Universität Berlin, Berlin, Germany

${ }^{4}$ Department of Clinical Medicine - Center for Functionally Integrative Neuroscience, Aarhus University, Aarhus, Denmark

${ }^{5}$ The Royal Academy of Music, Aarhus/Aalborg, Denmark

${ }^{6}$ School of Psychological Sciences, The University of Manchester, Manchester, UK

\section{Edited by:}

Andrea Bender, University of

Freiburg, Germany

Reviewed by:

Sarah Creel, University of California at San Diego, USA

Marcus Pearce, Goldsmiths,

University of London, UK

Sarah Dolscheid, Max Planck

Institute for Psycholinguistics,

Netherlands

\section{*Correspondence:}

M. Paula Roncaglia-Denissen, Research Group "Subcortical

Contributions to Comprehension," Department of Neuropsychology,

Max Planck Institute for Human Cognitive and Brain Sciences,

Stephanstraße 1a, D-04103 Leipzig,

Germany

e-mail: roncaglia@cbs.mpg.de

mprdenissen@gmail.com
As language rhythm relies partly on general acoustic properties, such as intensity and duration, mastering two languages with distinct rhythmic properties (i.e., stress position) may enhance musical rhythm perception. We investigated whether competence in a second language (L2) with different rhythmic properties than a $L 1$ affects musical rhythm aptitude. Turkish early (TELG) and late learners (TLLG) of German were compared to German late L2 learners of English (GLE) regarding their musical rhythmic aptitude. While Turkish and German present distinct linguistic rhythm and metric properties, German and English are rather similar in this regard. To account for inter-individual differences, we measured participants' short-term and working memory (WM) capacity, melodic aptitude, and time they spent listening to music. Both groups of Turkish L2 learners of German perceived rhythmic variations significantly better than German L2 learners of English. No differences were found between early and late learners' performance. Our findings suggest that mastering two languages with different rhythmic properties enhances musical rhythm perception, providing further evidence of shared cognitive resources between language and music.

Keywords: speech rhythm, L2, musical rhythm, rhythmic aptitude, Turkish, German, English

\section{INTRODUCTION}

Over the last few decades the impact of bilingualism and second language learning (L2) on cognitive processes has been the objective of many studies. Previous research reported a positive association between bilingualism and verbal and non-verbal intelligence (Peal and Lambert, 1962), problemsolving skills (Bialystok, 1999; Bialystok and Shapero, 2005), phonological memory (Service, 1992; Cheung, 1996), and working memory (WM) capacity in attention-impeding tasks (Yang et al., 2005).

Similarly, musical aptitude has been related to enhanced cognitive abilities (Draper and Gayle, 1987; Milovanov et al., 2008), such as general intelligence (Schellenberg, 2004), verbal memory (Brandler and Rammsayer, 2003), and to the enhanced processing of acoustic features embedded in complex musical contexts (Kraus and Chandrasekaran, 2010; Garza Villarreal et al., 2012; Vuust et al., 2012).

More recently, attention has been drawn to the association between musical aptitude and L2 learning (Milovanov and Tervaniemi, 2011). Studies report a positive effect of musical aptitude on second language skills, such as pronunciation (Milovanov et al., 2008) and phonological perception (Slevc and Miyake, 2006). In addition, it has been shown that a second language may enhance musical aptitude with respect to tone perception (Deutsch et al., 2006; Elmer et al., 2011). Nevertheless, as far as this study is concerned, the impact of second language learning on musical rhythm aptitude has not been investigated.

Similarly to rhythm in music, speech rhythm relies on acoustic prominence to create perceptual units that support the structuring and the organizing of speech flow (Lerdahl and Jackendoff, 1983; Nespor and Vogel, 1986; Hayes, 1989; Jackendoff, 1989). These perceptual units may constitute the basis of language rhythmic classifications as stress-timed, syllable-timed, and moratimed languages (Pike, 1945; Abercrombie, 1967; Ladefoged, 1975). In stress-timed languages, such as German and English, the unit of speech organization is the metric foot, i.e., a stressed syllable dominates at least one relatively weaker syllable (Hayes, 1985; Nespor and Vogel, 1986). In syllable-timed languages, such as Turkish and French, the syllable, regardless of stress, organizes and structures speech (Pike, 1945; Ladefoged, 1975; Cutler, 1994; Grabe and Low, 2002; Nazzi and Ramus, 2003). Finally, in mora-timed languages (e.g., Japanese), the mora, a subunit of the syllable, is regarded as the speech 
organization unit (Itô, 1989; Otake et al., 1993; Warner and Arai, 2001).

At the word level, rhythm operates by means of stress assignment, determining a language's metric preference. In terms of their metric preference, languages rely on the trochee or the iamb as their default metric pattern (Hayes, 1985; Hay and Diehl, 2007). The trochee is characterized by one stressed syllable followed by at least one relatively weaker syllable, while the iamb displays the opposite metric pattern, namely at least one unstressed syllable followed by a stressed one (Hayes, 1985). German and English provide examples of trochaic languages, while Turkish and French are iambic (Eisenberg, 1991; Inkelas and Orgun, 2003).

Implicit knowledge and the use of rhythmic properties such as the organization, perceptual units, and metric preference, constitute part of the speaker's competence in a language (Patel, 2008). Therefore, to master a second language, its rhythmic properties must be learned as part of the linguistic inventory of this language.

Despite speech rhythm being a language-specific ability, it is based on acoustic properties, such as intensity and duration that are found in other auditory domains such as music (Lerdahl and Jackendoff, 1983; Patel, 2003, 2008; Tincoff et al., 2005; Bispham, 2006). Properties of speech rhythm can therefore be considered domain-general properties (Jackendoff, 1989; Hay and Diehl, 2007). Mastering two languages with different rhythmic properties may thus enhance the sensitivity to these general acoustic properties when used in a specific language context.

This should be the case as speech rhythm may support language discrimination (Beckman, 1996; Ramus et al., 1999, 2003; Patel, 2008). Thus, if sensitivity to rhythmic properties in speech enhances the perception of rhythmic properties in music, such evidence would support the notion of shared resources in these two domains. It would also suggest that a domain-specific skill may be transferred to another cognitive domain, e.g., music (Perkins and Salomon, 1989).

Furthermore, if mastering languages with different rhythmic properties positively impacts musical rhythm perception, this effect could also be modulated by $\mathrm{L} 2$ age of acquisition (AoA). As some studies suggest, L2 learners have to make use of rhythmic information in an L2 to some extent to acquire this language (Goetry and Kolinsky, 2000). In addition, studies reveal that highly proficient late learners are sensitive to L2 rhythmic properties (Goetry and Kolinsky, 2000; Field, 2003; Trofimovich and Baker, 2006). However, one cannot disregard previous findings revealing that early L2 learners make use of rhythmic strategies in their dominant language only to segment words (Cutler et al., 1986, 1992; Otake et al., 1993). This would imply that similarly to phonology (Flege et al., 1999; Piske et al., 2001) the use of rhythmic strategies in speech segmentation would be constrained by the AoA. As contradictory as these findings may appear, the fact

\footnotetext{
${ }^{1}$ Even though several studies refuted the idea of an objective isochrony (Lea, 1974; Beckman, 1982; Wenk and Wioland, 1982), on which the traditional rhythmic classification of languages is based (Pike, 1945; Abercrombie, 1967; Ladefoged, 1975) the terms "stress-timed," "syllable-timed," and "moratimed" are still in use in the literature. For review and further discussion on this matter see (Patel, 2008).
}

that L2 learners superimpose rhythmic segmentation strategies of their dominant language onto an L2 does not exclude the possibility that they are sensitive to general acoustic properties underlying rhythm in both languages.

In the current research, we addressed two main issues. First, we investigated the impact of mastering languages with different rhythmic properties, such as metric preference and rhythmic classification, on musical rhythmic aptitude. This is motivated by their commonalities in temporal organization (rhythm) of music and language. In both domains rhythm organizes acoustic events in terms of timing and grouping, structuring the acoustic input in a hierarchical fashion by means of perceptual units (Lerdahl and Jackendoff, 1983; Nespor and Vogel, 1986; Hayes, 1989; Jackendoff, 1989).

Second, we explored whether musical rhythm can be modulated by L2 AoA. Even though much is known about the impact of AoA on different L2 skills, such as phonology, semantics, and syntax (Johnson and Newport, 1989; Weber-Fox and Neville, 1996; Flege et al., 1999; Piske et al., 2001; Wartenburger et al., 2003; Ojima et al., 2005; Clahsen and Felser, 2006; Hernandez and Li, 2007), the same does not hold true for L2 rhythm (Chun, 2002; Trofimovich and Baker, 2006). It could be that either the attainment of L2 rhythm is constrained by AoA as suggested by some research on rhythmic strategies in word segmentation (Cutler et al., 1986; Otake et al., 1993; Guion et al., 2004), or that it may be acquired with increased L2 exposure and proficiency (Goetry and Kolinsky, 2000; Field, 2003; Trofimovich and Baker, 2006).

In order to address these issues, we tested Turkish early (TELG) and late L2 learners of German (TLLG) and German late L2 learners of English (GLE) with respect to their musical rhythmic aptitude. Whereas German and English share rhythmic classification and metric preferences (Pike, 1945; Eisenberg, 1991; Cummins and Port, 1998), Turkish and German represent rather an interesting contrast when considering their respective rhythmic properties. While German is a stress-timed language with a metric preference for the trochee, Turkish is syllable-timed and uses the iamb as its default metric pattern (Eisenberg, 1991; Grabe and Low, 2002; Inkelas and Orgun, 2003; Nazzi and Ramus, 2003; Topbas, 2006; Höhle et al., 2009).

In order to control for individual differences that may influence participants' performance, such as cognitive and musical ability, participants were tested in terms of their short-term memory (STM) and working memory (WM) capacities. Short-term memory regards the ability to store given, and relatively unprocessed, information for a short period of time (Baddeley, 2003; Conway et al., 2005). Working memory characterizes the ability to maintain information actively while cognitive processes are being executed (Baddeley, 2003; Conway et al., 2005). Previous research suggests that STM and WM capacity correlate with general intelligence, thus providing an indicator of cognitive resources (Daneman and Carpenter, 1980; Engle et al., 1999; Oberauer et al., 2000; Conway et al., 2005; Unsworth and Engle, 2007).

In addition, participants were asked about their musical background, weekly exposure to music, and were tested for their musical aptitude, by means of a melody aptitude test. Next to rhythm, the perception of pitch variation, as in melody and 
harmony, is considered one of the two fundamental aspects of music (Lerdahl and Jackendoff, 1983) and is extensively used as an indicator of musical aptitude (Seashore et al., 1960; Gordon, 1969, 2007; Wallentin et al., 2010).

Therefore, by controlling for differences in participants' cognitive ability, musical aptitude, and weekly exposure to music, we expected differences in rhythmic aptitude to be explained by the mastery of languages with distinct rhythmic properties.

\section{MATERIALS AND METHODS PARTICIPANTS}

Eighty-five right-handed participants were assigned to three experimental groups, i.e., 27 Turkish late L2 learners of German (13 females, $M_{\text {age }}=29.11, S D=3.85$, mean age of L2 first exposure, AoL2FE $=20.03, S D=6.40)$, 26 Turkish early L2 learners of German (12 females, $M_{\mathrm{age}}=26.80, S D=4.48, M_{\text {AoL2 } \mathrm{FE}}=$ $1.03, S D=0.19)$ and 32 German late L2 learners of English (16 females, $M_{\text {age }}=25.71, S D=2.55, M_{\text {AoL2FE }}=10.04, S D=$ 1.27). All participants were non-musicians. $64.7 \%$ of the participants reported playing no instrument at all, while $35.3 \%$ reported playing an instrument for an average of 4.75 years $(S D=3.83)$. Participants were either university students or recent graduates. They were paid for their participation. None of the participants reported any neurological impairment or hearing deficit, and all had normal or corrected-to-normal vision. This study was approved by the ethics committee of the University of Leipzig and all participants gave their written informed consent for data collection, use, and publication.

\section{SECOND LANGUAGE ASSESSMENT AND LANGUAGE HISTORY OUESTIONNAIRE}

All participants were given a language history questionnaire concerning both their L1 and L2. With this questionnaire, we assessed language competence, such as listening, writing, reading and speaking skills, age of first exposure to the languages, situations in which each language was acquired, and current language use. Self-reported language questionnaires have been successfully used to assess L1 and L2 acquisition, history and competence skills (Elston-Güttler et al., 2005; Marian et al., 2007; Schmidt-Kassow et al., 2011a). Based on the results of the assessment and on the participants' own perception of their language preference, English and German were regarded as the second language among German and in both Turkish L2 learner groups, respectively.

\section{THE MUSICAL EAR TEST}

As a rhythmic aptitude measure, we used the rhythmic subset of the Musical Ear Test (MET; Wallentin et al., 2010). The MET rhythmic subset consists of 52 rhythmic pairs, which are formed by either two identical or two different rhythmic phrases. All rhythmic phrases were recorded using wood blocks and were 411 beats long. Rhythmic phrases have a duration of one measure and were played at $100 \mathrm{bpm}$. Trials constituted two distinct rhythmic phrases and differed only by one rhythmic change. Rhythmic complexity was achieved by including triplets in 21 trials, while the other 31 trials presented even beat subdivisions. Thirty-seven trials begin on the downbeat while the remaining trials begin on the beat removed. The order, in which these features occurred, was randomized.
In its original version, the MET involves an answer sheet to be filled out by the participants. Additionally, the test provides participants with auditory instructions in English prior to and during the test to introduce each trial. We created an adapted version, in which instructions in German were presented visually prior to the test, i.e., in the training phase, but not before each single trial.

\section{SHORT-TERM MEMORY AND WORKING MEMORY MEASURES}

In the current study, we used the Mottier Test, MT (Mottier, 1951), a non-word repetition test, as a measure of short-term memory. The MT is composed of sets of 6 non-words, ranging from 2 to 6 syllables each. The stimulus material presented a constant syllabic structure of one consonant followed by one vowel, i.e., CV. The non-words were spoken by a female professional speaker and presented to participants via headphones.

We used the backward digit span (BDS), a WM measure involving information storage and transformation (Oberauer et al., 2000; Süß et al., 2002). The BDS version adopted in the current study is composed of 14 sets of 2 trials, ranging from 2 to 8 numbers. The numbers were spoken by a female German native speaker and recorded at a rate of one number per second. Numbers were presented via headphones and participants had to recall them in the reverse order of which they were presented.

\section{MELODIC APTITUDE TEST}

To measure participants' melodic aptitude, the melodic subset from the MET was used (Wallentin et al., 2010). This subset consists of 52 melodic pairs, formed by two identical or two different melodic phrases. Melodic phrases consisted of 3-8 tones and had a duration of one measure and were played at $100 \mathrm{bpm}$. Different trials (26 pairs) contained pitch violation and in half of them the pitch violation also characterized a violation in the pitch contour. Twenty-five trials were constituted by non-diatonic tones, while 7 trials were in the Minor key and 20 in the Major. The order, in which these features occurred, was randomized.

\section{PROCEDURES}

Participants were tested individually in a quiet room. The tests were administered in a pseudo-randomized order on a computer and each individual session lasted $\sim 1 \mathrm{~h}$. Participants received written instructions for each test, either on separate instruction sheets or presented on the computer screen. Before each test, practice trials were provided and participants were allowed to repeat them until the test was understood correctly. At the end of the session, participants were asked about the average time they spent listening to music in a week (number of hours). Furthermore, participants' information about their L1 and L2 was assessed.

\section{The Musical Ear Test}

The MET rhythmic subset was presented via headphones using a computer. While participants listened to rhythmic phrases, a white star was presented in the center of a black screen, providing a visual cue to attend to during stimulus presentation. Participants judged if the presented rhythmic pair comprised identical or different phrases. At the end of a rhythm trial, the white star was replaced by the words "JA" (yes) and "NEIN" (no) placed at middle height and at opposite sides of the screen, 
matching the positions of the response keys. Participants had $1 \mathrm{~s}$ to press the corresponding answer key. The position of the correct-response key was counter-balanced across participants.

\section{Mottier Test and backward digit span}

Participants self-initiated the Mottier Test by pressing the space key. With a visual cue placed in the center of the computer screen, participants heard the first non-word and were instructed to repeat it as accurately and as fast as possible, after which the next non-word was presented and the same procedure was repeated. At the end of each trial set, participants were given a short break and self-determined when the test should be re-initiated. Participants' responses were computed ad-hoc by the experimenter with the help of a response sheet, as well as being recorded via the computer. The test was terminated when participants failed to recall a minimum of 4 items of the same trial set correctly. Scoring was based on the total number of correctly recalled non-words.

In the BDS, participants listened to the sequences of numbers via headphones while facing away from the computer. At the end of the numerical trial, participants were asked to repeat the numbers in the reversed order of their presentation. The test was terminated when participants failed to recall two trials of the same set. Scoring was given according to the total number of trials correctly recalled.

\section{Melodic aptitude test}

The MET melodic subset was presented via headphones using a computer. Participants listened to the melodic phrases while presented with a visual cue in the center of a black screen. Participants were to judge if the presented melodic pair consisted of identical or different phrases. With the end of the melodic trial, participants were presented with the words "JA" (yes) and "NEIN" (no), matching the positions of the response keys. Participants had $1 \mathrm{~s}$ to press the corresponding answer key. Correct-response key position was counter-balanced across participants.

\section{Statistical analysis}

German late L2 learners of English were divided into three groups according to their self-reported English proficiency level, i.e., having very good to excellent writing and speaking skills, having good writing and speaking skills and having good speaking, but not writing skills in English. An ANOVA was conducted with a between-subjects factor (proficiency) and their rhythmic performance as dependent variable. This allowed to explore whether their knowledge of another language (English) with similar rhythmic properties to German (e.g., Pike, 1945;
Jusczyk et al., 1993) would affect their musical rhythmic performance. Furthermore, all participants were divided into three groups, creating a between-subjects factor group (German late L2 learners of English, Turkish early and late L2 learners of German). An analysis of covariance (ANCOVA) was computed with group as a between-subjects factor and participants' scores in the MET rhythmic subset as the dependent variable. Participants' scores in the cognitive tests, i.e., the MT and the BDS, their melodic aptitude as well as their weekly exposure to music (number of hours per week) were used as covariates. To ensure that the assumption of independence of the covariates (Miller and Chapman, 2001) was not violated, additional ANOVAs were conducted for each cognitive measure, i.e., BDS, MT, and melodic aptitude using group as a between-subjects factor. Along the same lines, a chi-square test was conducted to compare the three groups in terms of their weekly musical exposure.

\section{RESULTS}

Descriptive results and reliability tests are summarized in Table $\mathbf{1 .}$ In Table 2 language skills of the three L2 learner groups are shown.

\section{STATISTICAL ANALYSIS}

Results of the ANOVA conducted with German L2 learners revealed no significant effect of the participants' English skills on their rhythmic performance, $F_{(2,39)}=0.88, p>0.1$. An ANOVA investigating the independence of covariates as well as the chisquare test revealed that none of the covariates vary across groups, all $p s>0.05$. For the rhythmic aptitude test, the conducted ANCOVA revealed a significant effect of group, $F_{(2,78)}=9.29$, $p<0.001, \omega^{2}=0.32$.

Pairwise comparison of the adjusted means of participants' scores using the Holm's Sequential Bonferroni correction revealed a significant difference between German late L2 learners of English $(M=64.60, S E=1.46)$ and Turkish late L2 learners of German $(M=71.78, S E=1.57 ; p=0.0002)$. In addition, German L2 learners' performance was significantly different from Turkish early L2 learners' ( $M=70.15, S E=1.91 ; p=0.0023)$. A comparison between the two Turkish L2 learner groups did not yield significant differences $(p=0.40)$.

These findings are consistent with our initial hypothesis, namely despite controlling for individuals' cognitive abilities and melodic aptitude, group differences in rhythmic aptitude are confirmed.

Table 1 | Reliability tests and participants' score for each conducted task.

\begin{tabular}{|c|c|c|c|c|c|c|c|}
\hline \multirow[t]{2}{*}{ Tasks } & \multirow[t]{2}{*}{$\begin{array}{l}\text { Reliability } \\
\text { (Cronbach's } \alpha \text { ) }\end{array}$} & \multicolumn{2}{|c|}{$\begin{array}{c}\text { German late L2 learners } \\
\text { of English }\end{array}$} & \multicolumn{2}{|c|}{$\begin{array}{c}\text { Turkish early L2 learners } \\
\text { of German }\end{array}$} & \multicolumn{2}{|c|}{$\begin{array}{c}\text { Turkish late L2 learners } \\
\text { of German }\end{array}$} \\
\hline & & $M$ & $S D$ & $M$ & $S D$ & $M$ & $S D$ \\
\hline Rhythmic aptitude test (MET subset) & 0.627 & 64.50 & 8.30 & 70.15 & 9.76 & 71.78 & 8.17 \\
\hline Mottier Test & 0.896 & 27.75 & 2.88 & 26.50 & 4.50 & 26.44 & 5.34 \\
\hline Backward digit span & 0.694 & 8.53 & 2.79 & 7.73 & 1.88 & 7.18 & 2.30 \\
\hline
\end{tabular}


Table 2 | Language skills of L2 learners.

\begin{tabular}{|c|c|c|c|c|c|c|}
\hline \multirow[t]{2}{*}{ Language skill (\%) } & \multicolumn{2}{|c|}{$\begin{array}{c}\text { German late learners } \\
\text { of English }\end{array}$} & \multicolumn{2}{|c|}{$\begin{array}{c}\text { Turkish early learners } \\
\text { of German }\end{array}$} & \multicolumn{2}{|c|}{$\begin{array}{c}\text { Turkish late learners } \\
\text { of German }\end{array}$} \\
\hline & $M$ & $S D$ & $M$ & $S D$ & $M$ & $S D$ \\
\hline L1 Listening & 99.67 & 1.79 & 94.81 & 10.51 & 99.25 & 2.66 \\
\hline L2 Listening & 76.78 & 13.62 & 99.61 & 1.96 & 85.92 & 11.52 \\
\hline L1 Reading & 99.67 & 1.79 & 85.38 & 20.63 & 99.25 & 2.66 \\
\hline L2 Reading & 81.42 & 10.78 & 97.77 & 4.23 & 82.22 & 11.87 \\
\hline L1 Language independence & 100 & - & 94.44 & 10.50 & 99.62 & 1.92 \\
\hline L2 Language independence & 82.56 & 28.72 & 98.14 & 5.57 & 80.37 & 15.05 \\
\hline
\end{tabular}

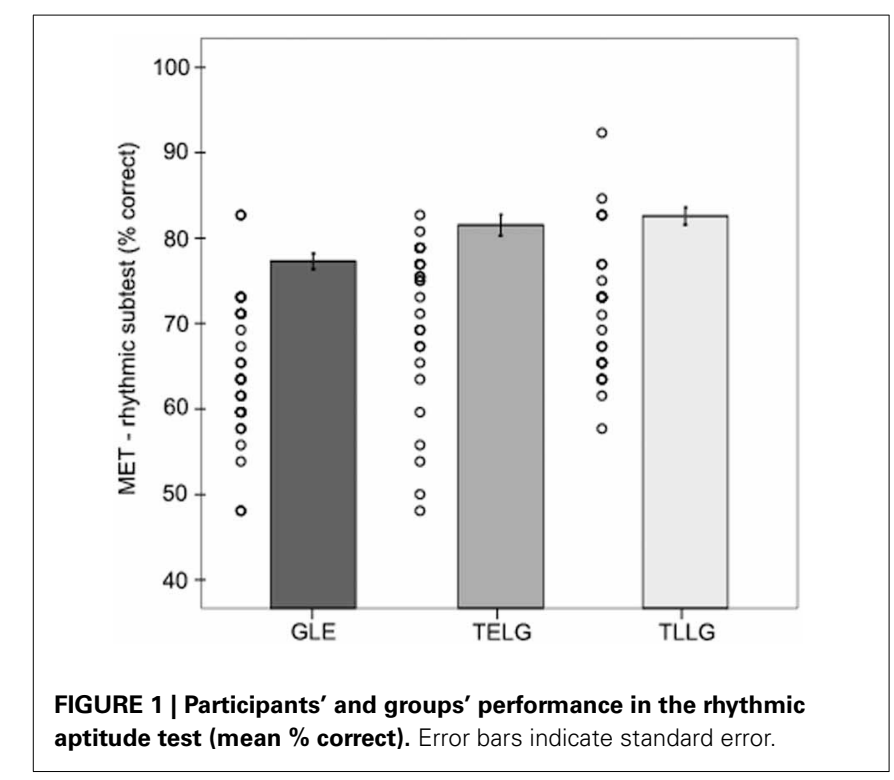

Rhythmic performance of all participants (German late L2 learners of English, Turkish early and late L2 learners of German) in the MET rhythmic subset are depicted in Figure $\mathbf{1 .}$

\section{DISCUSSION}

In the current study, we investigated the musical rhythm aptitude of Turkish early and late L2 learners of German and that of German late L2 learners of English to address two main issues. First, whether mastering languages with different rhythmic properties, such as Turkish and German, can enhance rhythm perception in music, and second, whether musical rhythm aptitude is modulated by L2 AoA.

Regarding the first question, results show that when controlling for participants' cognitive abilities i.e., STM and WM capacities, and for melodic aptitude, both Turkish L2 learner groups outperformed German L2 learners of English in terms of their rhythm aptitude.

Our findings suggest that specific linguistic properties, i.e., rhythmic information, may be transferred to the musical domain. This could be the case as individuals may recognize acoustic similarities in music and language, e.g., stress (Lerdahl and Jackendoff, 1983; Hayes, 1989; Jackendoff, 1989; Patel, 2003).
This, in turn, may transfer from one domain to the other (Perkins and Salomon, 1989; Magne et al., 2003; Schön et al., 2004; Vuust et al., 2011).

Thus, being sensitive to different rhythmic properties as a result of mastering two languages may constitute a domainspecific ability, which results from domain-general skills (Perkins and Salomon, 1989; Salomon and Perkins, 1989), namely the ability to structure and organize events in time, i.e., rhythm (Jackendoff, 1989; Cummins and Port, 1998). This would parallel with recent findings in music research that a domain-specific skill enhances an individual's acoustic perception (Pantev et al., 2001; Kraus and Chandrasekaran, 2010; Vuust et al., 2012).

In addition, as rhythm is a valuable cue to discriminate between languages (Ramus, 2002; Nazzi and Ramus, 2003), perhaps L2 learners whose L1 is fundamentally different from their L2 with respect to rhythmic properties are more attentive and sensitive to acoustic variations than those L2 learners whose L1 and L2 rhythmic properties do not differ (e.g., German and English). This may lead to improved language recognition and selection. Given that Turkish and German are rather diverse concerning their rhythmic properties, rhythmic information may facilitate language selection and may allow cognitive resources to be allocated to other linguistic processes where they are most needed, such as speech segmentation.

Nevertheless, one may argue that our results could alternatively be explained by L2 learners' exposure to a different musical culture, namely Turkish music. In this sense, the higher level of rhythmic complexity found in Turkish music, such as the presence of a non-isochronous meter, so rare in Western music (Bates, 2010; Hannon et al., 2012), may contribute to higher rhythmic sensitivity among Turkish L2 learners. Thus, enhanced perception of rhythmic patterns could be influenced by the familiarity with a certain rhythm, and therefore, by a culture-specific listening experience (Hannon et al., 2012). Despite this reasoning, one should consider that the rhythmic variations participants were presented with can be found both in Western and Turkish music. Furthermore, rhythmic sentences varied with respect to one beat only, relativizing rhythmic complexity. As such, Turkish L2 learners of German should not start out with an advantage over German L2 learners of English in terms of musical rhythmic perception.

Additionally, one may think that our findings result from the nature of the Turkish language. This should not be the case, 
because Turkish and German present the same fundamental features establishing acoustic prominence in speech, i.e., duration and intensity creating lexical stress. Hence, it is unlikely that Turkish controls should have a rhythmic advantage over German controls in terms of their ability to discriminate these rhythmic properties. In addition, in a recent study Schmidt-Kassow et al. (2011b) reported that French native speakers detect stress variation in tonal sequences comparably to native speakers of German. Hence, their findings support the idea that no particular rhythmic class, i.e., stress-timing or syllable-timing, leads to an advantage in terms of rhythmic discrimination in a nonlinguistic context. Nevertheless, in order to rule out the possibility that enhanced musical rhythmic perception may rely on the mastery of Turkish, Turkish monolingual controls should be further investigated.

Regarding the second issue addressed in this research, namely whether L2 AoA influences general rhythm perception, the current results indicate that musical rhythm perception does not seem to be subject to L2 AoA. The fact that both groups of Turkish L2 learners benefit from L1 and L2 rhythmic diversity seems to indicate that L2 speakers are sensitive and may learn, to some degree, L2 rhythmic properties beyond a sensitive period (Bailey et al., 1999; Goetry and Kolinsky, 2000; Field, 2003; Trofimovich and Baker, 2006).

This could be the case because the prominence created by rhythm is based on temporal acoustic perception, which can be learned and improved later on in life (Alain et al., 2007; Dahmen and King, 2007; Van Wassenhove and Nagarajan, 2007). Thus, speech rhythm could be less constrained by L2 AoA than other linguistic skills, such as complex syntactic processing and phonology (Johnson and Newport, 1989; Weber-Fox and Neville, 1996; Flege et al., 1999; Piske et al., 2001; Papadopoulou, 2005; Clahsen and Felser, 2006; Hernandez and Li, 2007).

In view of the current results, some questions remain. If enhanced musical rhythm aptitude found among L2 learners results from the selection of languages with distinct rhythmic properties, this could suggest that these L2 learners are also better in discriminating languages based on rhythmic information. Therefore, further investigations regarding language discrimination based on rhythmic properties should be carried

\section{REFERENCES}

Abercrombie, D. (1967). Elements of General Phonetics. Edinburgh: University Press.

Alain, C., Snyder, J. S., He, Y., and Reinke, K. S. (2007). Changes in auditory cortex parallel rapid perceptual learning. Cereb. Cortex 17, 1074-1084. doi: 10.1093/cercor/ bhlo18

Baddeley, A. (2003). Working memory and language: an overview. J. Commun. Disord. 36, 189-208. doi: $\quad 10.1016 / 50021-9924(03)$ 00019-4

Bailey, T. M., Plunkett, K., and Scarpa, E. (1999). A cross- linguistic study in learning prosodic rhythms: rules,

out with L2 learners, whose L1 and L2 have different rhythmic properties.

Moreover, L2 learners from languages sharing some of their rhythmic properties, such as metric preference (e.g., German and Italian) or rhythmic organization (e.g., Spanish and French), should be tested. This could provide a more complete understanding of which rhythmic properties contribute more or less to an enhancement in musical rhythmic aptitude.

Such investigations should shed more light on if and how mastering languages with different rhythmic properties (e.g., stress position) may affect the ability to discriminate between languages, facilitating the selection of the target language and, therefore, speech processing.

\section{CONCLUSION}

Our study is a first investigation on how distinct rhythmic properties in first and second languages may enhance musical rhythm aptitude. Results confirm an enhanced musical rhythm aptitude in Turkish early and late L2 learners of German compared to German late L2 learners of English. These findings should be taken as a starting point for future studies investigating the shared properties between language and music in the context of second language learning. Research into this specific topic will eventually provide a better understanding of how acoustic properties (e.g., sound duration and intensity) may be perceived and used across domains.

\section{ACKNOWLEDGMENTS}

The authors would like to thank Patricia E. Román and Jaap J. A. Denissen for their helpful comments and thoughts on an early draft of this paper. M. Paula Roncaglia-Denissen is supported by the Max Planck International Research Network on Aging (MaxNetAging). Sonja A. Kotz is supported by an ITN European Grant: "Europe, Brain and Music: New perspectives for stimulating cognitive and sensory processes (EBRAMUS)."

\section{SUPPLEMENTARY MATERIAL}

The Supplementary Material for this article can be found online at: http://www.frontiersin.org/Cognitive_Science/10.3389/ fpsyg.2013.00645/abstract

70, 636-644. doi: $10.1111 / 1467-$ 8624.00046

constraints, and similarity. Lang. Speech 42, 1-38. doi: 10.1177/ 00238309990420010101

Bates, E. (2010). Music in Turkey: Experiencing Music, Expressing Culture. New York, NY: Oxford University Press.

Beckman, M. E. (1982). Segment duration and the "Mora" in Japanese. Phonetica 39, 113-135. doi: 10.1159/ 000261655

Beckman, M. E. (1996). The parsing of prosody. Lang. Cogn. Process. 11, 17-68. doi: 10.1080/ 016909696387213

Bialystok, E. (1999). Cognitive complexity and attentional control in the bilingual mind. Child Dev.
Bialystok, E., and Shapero, D. (2005). Ambiguous benefits: the effect of bilingualism on reversing ambigudoi: $\quad 10.1111 /$ j.1467-7687.2005. 00451.x

Bispham, J. (2006). Rhythm in Music: what is it? who has it? and why? Music Percept. Interdiscip. J. 24, 125-134. doi: 10.1525/mp.2006.24. 2.125

Brandler, S., and Rammsayer, T. H. (2003). Differences in mental abilities between musicians and non-musicians. Psychol. Music 31, 123-138. ous figures. Dev. Sci. 8, 595-604. doi: $\quad 10.1177 / 0305735603031$ 002290

Cheung, H. (1996). Nonword span as a unique predictor of secondlanguage vocabulary language. Dev. Psychol. 32, 867-873. doi: 10.1037/ 0012-1649.32.5.867

Chun, D. M. (2002). Discourse Intonation in L2: From Theory and Research to Practice. Amsterdam; Philadelphia, PA: John Benjamins Publishing Company.

Clahsen, H., and Felser, C. (2006). How native-like is non-native language processing? Trends Cogn. Sci. 10, 564-570. doi: 10.1016/j.tics. 2006.10.002 
Conway, A. R. A., Kane, M. J., Bunting, M. F., Hambrick, D. Z., Wilhelm, O., and Engle, R. W. (2005). Working memory span tasks: a methodological review and user's guide. Psychon. Bull. Rev. 12, 769-786. doi: 10.3758/ BF03196772

Cummins, F., and Port, R. (1998). Rhythmic constraints on stress timing in English. J. Phon. 145-171. doi: 10.1006/jpho.1998.0070

Cutler, A. (1994). The Perception of rhythm in language. Cognition 79-81. doi: 10.1016/00100277(94)90021-3

Cutler, A., Mehler, J., Norris, D., and Segui, J. (1986). The syllable's differing role in the segmentation of French and English. J. Mem. Lang. 25, 385-400. doi: 10.1016/0749596X(86)90033-1

Cutler, A., Mehler, J., Norris, D., and Segui, J. (1992). The monolingual nature of speech segmentation by bilinguals. Cogn. Psychol. 24, 381-410. doi: 10.1016/00100285(92)90012-Q

Dahmen, J. C., and King, A. J. (2007). Learning to hear: plasticity of auditory cortical processing. Curr. Opin. Neurobiol. 17, 456-464. doi: 10.1016/j.conb.2007.07.004

Daneman, M., and Carpenter, P. A. (1980). Individual differences in working memory and reading. J. Verbal Learn. Verbal Behav. 19, 450-466. doi: 10.1016/S0022-5371(80)90312-6

Deutsch, D., Henthorn, T., Marvin, E., and $\mathrm{Xu}, \mathrm{H}$. (2006). Absolute pitch among American and Chinese conservatory students: prevalence differences, and evidence for a speech-related critical period. J. Acoust. Soc. Am. 119, 719-722. doi: 10.1121/1.2151799

Draper, T. W., and Gayle, C. (1987). "An analysis of historical reasons for teaching music to young children: Is it the same old song?", in Music Child Development, eds J. C. Peery, T. W. Peery, and T. W. Draper (New York, NY: Springer-Verlag), 194-205.

Eisenberg, N. (1991). Syllabische struktur und wortakzent. prinzipien der prosodik deutscher wörter. Z. Fuer Sprachwiss. 10, 37-64. doi: 10.1515/ zfsw.1991.10.1.37

Elmer, S., Meyer, M., Marrama, L., and Jäncke, L. (2011). Intensive language training and attention modulate the involvement of fronto-parietal regions during a non-verbal auditory discrimination task. Eur. J. Neurosci. 34, 165-175. doi: 10.1111/ j.1460-9568.2011.07728.x

Elston-Güttler, K. E., Paulmann, S., and Kotz, S. A. (2005). Who's in control? proficiency and L1 influence on L2 processing. J. Cogn. Neurosci. 17, 1593-1610. doi: 10.1162/089892905774597245

Engle, R. W., Tuholski, S. W., Laughlin, J. E., and Conway, A. R. A. (1999). Working memory, short-term memory, and general fluid intelligence: a latent-variable approach. J. Exp. Psychol. Gen. 128, 309-331. doi: 10.1037/0096-3445. 128.3.309

Field, J. (2003). Promoting perception: lexical segmentation in L2 listening. ELT J. 57, 325-334. doi: 10.1093/elt/57.4.325

Flege, J. E., Yeni-Komshian, G. H., and Liu, S. (1999). Age constraints on second-language acquisition. J. Mem. Lang. 41, 78-104. doi: 10.1006/jmla.1999.2638

Garza Villarreal, E. A., Brattico, E., Vase, L., Østergaard, L., and Vuust, P. (2012). Superior analgesic effect of an active distraction versus pleasant unfamiliar sounds and music: the influence of emotion and cognitive style. PLoS ONE 7:e29397. doi: 10.1371/journal.pone.0029397

Goetry, V., and Kolinsky, R. (2000). The role of rhythmic cues for speech segmentation in monolingual and bilingual listeners. Psychol. Belg. 40 115-152.

Gordon, E. E. (1969). Intercorrelations among musical aptitude profile and seashore measures of musical talents subtests. J. Res. Music Educ. 17, 263. doi: $10.2307 / 3343874$

Gordon, E. E. (2007). Learning Sequences in Music: a Contemporary Music Learning Theory. Chicago, IL: GIA Publications.

Grabe, E., and Low, E. L. (2002). "Durational variability in speech and the rhythm class hypothesis," in Laboratory Phonology 7, eds C. Gussenhoven and N. Warner (Berlin: Mouton de Gruyter), 515-546.

Guion, S. G., Harada, T., and Clark, J. J. (2004). Early and late SpanishEnglish bilinguals' acquisition of English word stress patterns. Biling. Lang. Cogn. 7, 207-226. doi: 10.1017/S1366728904001592

Hannon, E. E., Soley, G., and Ullal, S. (2012). Familiarity overrides complexity in rhythm perception: a cross-cultural comparison of American and Turkish listeners. J. Exp. Psychol. Hum. Percept. Perform. 38, 543-548. doi: 10.3758/ BF03194458

Hay, J., and Diehl, R. (2007). Perception of rhythmic grouping: testing the iambic/trochaic law. Atten. Percept. Psychophys. 69, 113-122. doi: 10.3758/BF03194458
Hayes, B. (1985). Iambic and trochaic rhythm in stress rules. Proc. Berkeley Linguist. Soc. 11, 429-446.

Hayes, B. (1989). "The prosodic hierarchy in meter," in Phonetics and Phonology. Rhythm and Meter, eds P. Kiparsky and G. Youmans (San Diego, CA: Academic Press), 201-260.

Hernandez, A. E., and Li, P. (2007). Age of acquisition: its neural and computational mechanisms. Psychol. Bull. 133, 638. doi: 10.1037/0033-2909.133.4.638

Höhle, B., Bijeljac-Babic, R., Herold, B., Weissenborn, J., and Nazzi, T. (2009). Language specific prosodic preferences during the first half year of life: evidence from German and French infants. Infant Behav. Dev. 32, 262-274. doi: 10.1016/j.infbeh.2009.03.004

Inkelas, S., and Orgun, O. (2003). Turkish Stress: a review. Phonology 20, 139-161. doi: 10.1017/ S0952675703004482

Itô, J. (1989). A prosodic theory of epenthesis. Nat. Lang. Linguist. Theory 7, 217-259. doi: 10.1007/BF00138077

Jackendoff, R. (1989). "A comparison of rhythmic structures in music and language," in Phonetics and Phonology. Rhythm and Meter, eds P. Kiparsky and G. Youmans (San Diego, CA: Academic Press), 15-44.

Johnson, J. S., and Newport, E. L. (1989). Critical period effects in second language learning: the influence of maturational state on the acquisition of English as a second language. Cogn. Psychol. 21, 60-99. doi: 10.1016/0010-0285(89)90003-0

Jusczyk, P. W., Cutler, A., and Redanz, N. J. (1993). Infants' preference for the predominant stress patterns of english words. Child Dev. 64, 675-687. doi: 10.2307/1131210

Kraus, N., and Chandrasekaran, B. (2010). Music training for the development of auditory skills. Nat. Rev. Neurosci. 11, 599-605. doi: $10.1038 / \mathrm{nrn} 2882$

Ladefoged, P. (1975). A Course in Phonetics. New York, NY: Jarcourt. Brace and Jovanovich.

Lea, W. A. (1974). Prosodic Aids to Speech Recognition. IV. A General Strategy for Prosodically-Guided Speech Understanding. Advance Research Projects Agency Report No. PX10791, St. Paul, MN: Sperry Univac.

Lerdahl, F., and Jackendoff, R. (1983). A Generative Theory of Tonal Music. Cambridge, MA: MIT Press.

Magne, C., Schön, D., and Besson, M. (2003). Prosodic and melodic processing in adults and children: behavioral and electrophysiologic approaches. Ann. N.Y. Acad. Sci. 999, 461-476. doi: 10.1196/annals. 1284.056

Marian, V., Blumenfeld, H. K., and Kaushanskaya, M. (2007). The Language Experience and Proficiency Questionnaire (LEAPQ): assessing language profiles in bilinguals and multilinguals. J. Speech Lang. Hear. Res. 50, 940-967. doi: 10.1044/1092-4388 (2007/067)

Miller, G. A., and Chapman, J. P. (2001). Misunderstanding analysis of covariance. J. Abnorm. Psychol. $110,40-48$. doi: 10.1037/0021843X.110.1.40

Milovanov, R., Huotilainen, M., Välimäki, V., Esquef, P. A. A., and Tervaniemi, M. (2008). Musical aptitude and second language pronunciation skills in school-aged children: neural and behavioral evidence. Brain Res. 1194, 81-89. doi: 10.1016/j.brainres.2007.11.042

Milovanov, R., and Tervaniemi, M. (2011). The Interplay between musical and linguistic aptitudes: a review. Front. Psychol. 2:321. doi: 10.3389/fpsyg.2011.00321

Mottier, G. (1951). Über Untersuchungen der Sprache lesegestörter Kinder. Folia Phoniatr. Logop. 3, 170-177. doi: 10.1159/ 000262507

Nazzi, T., and Ramus, F. (2003). Perception and acquisition of linguistic rhythm by infants. Speech Commun. 41, 233-243. doi: 10.1016/S0167-6393(02)00106-1

Nespor, M., and Vogel, I. (1986). Prosodic Phonology. Dordrecht: Foris Publications.

Oberauer, K., Süß, H.-M., Schulze, R., Wilhelm, O., and Wittmann, W. W. (2000). Working memory capacity - facets of a cognitive ability construct. Pers. Individ. Differ. 29, 1017-1045. doi: 10.1016/S01918869(99)00251-2

Ojima, S., Nakata, H., and Kakigi, R. (2005). An ERP study of second language learning after childhood: effects of proficiency. J. Cogn. Neurosci. 17, 1212-1228. doi: 10.1162/0898929055002436

Otake, T., Hatano, G., Cutler, A., and Mehler, J. (1993). Mora or syllable? Speech segmentation in Japanese. J. Mem. Lang. 32, 258-278. doi: 10.1006/jmla.1993.1014

Pantev, C., Roberts, I. E., Schulz, M., Engelien, A., and Ross, B. (2001). Timbre-specific enhancement of auditory cortical representations in musicians. Neuroreport 12, 169-174. doi: 10.1097/00001756200101220-00041 
Papadopoulou, D. (2005). Readingtime studies of second language ambiguity resolution. Second Lang. Res. 21, 98-120. doi: 10.1191/ $0267658305 \mathrm{sr} 254 \mathrm{oa}$

Patel, A. D. (2003). Rhythm in language and music. Ann. N.Y. Acad. Sci. 999, 140-143. doi: 10.1196/annals. 1284.015

Patel, A. D. (2008). Music, Language and the Brain. New York, NY: Oxford University Press.

Peal, E., and Lambert, W. E. (1962). The relation of bilingualism to intelligence. Psychol. Monogr. Gen. Appl. 76, 1-23. doi: 10.1037/ h0093840

Perkins, D. N., and Salomon, G. (1989). Are cognitive skills contextbound? Educ. Res. 18, 16. doi: 10.3102/0013189X018001016

Pike, K. L. (1945). The Intonation of American English. Ann Arbor, MI: University of Michigan Press.

Piske, T., MacKay, I. R. A., and Flege, J. E. (2001). Factors affecting degree of foreign accent in an L2: a review. J. Phon. 29, 191-215. doi: 10.1006/jpho.2001.0134

Ramus, F. (2002). Language discrimination by newborns: teasing apart phonotactic, rhythmic, and intonational cues. Annu. Rev. Lang. Acquis. 2, 85-115. doi: 10.1075/arla. 2.05ram

Ramus, F., Dupoux, E., and Mehler, J. (2003). "The psychological reality of rhythm classes: Perceptual studies," in ICPHS, 337-342.

Ramus, F., Nespor, M., and Mehler, J. (1999). Correlates of linguistic rhythm in the speech signal. Cognition 73, 265-292. doi: 10.1016/ S0010-0277(99)00058-X

Salomon, G., and Perkins, D. N. (1989). Rocky roads to transfer: rethinking mechanism of a neglected phenomenon. Educ. Psychol. 24, 113-142. doi: 10.1207/s15326985 ep2402_1

Schellenberg, E. G. (2004). Music lessons enhance IQ. Psychol. Sci. 15, 511-514. doi: 10.1111/j.09567976.2004.00711.x
Schmidt-Kassow, M., RoncagliaDenissen, M. P., and Kotz, S. A. (2011a). Why pitch sensitivity matters: event-related potential evidence of metric and syntactic violation detection among Spanish late learners of German. Front. Lang. Sci. 2:131. doi: 10.3389/fpsyg.2011.00131

Schmidt-Kassow, M., Rothermich, K., Schwartze, M., and Kotz, S. A. (2011b). Did you get the beat? Late proficient French-German learners extract strong-weak patterns in tonal but not in linguistic sequences. Neuroimage 54, 568-576. doi: 10.1016/j.neuroimage.2010.07.062

Schön, D., Magne, C., and Besson, M. (2004). The music of speech: music training facilitates pitch processing in both music and language. Psychophysiology 41, 341-349. doi: 10.1111/1469-8986.00172.x

Seashore, C. E., Lewis, D., and Saetveit, J. (1960). Seashore Measures of Musical Talents. New York, NY: Psychological Corporation.

Service, E. (1992). Phonology, working memory and foreign language learning. Q. J. Exp. Psychol. 45, 21-50. doi: 10.1080/ 14640749208401314

Slevc, L. R., and Miyake, A. (2006). Individual differences in secondlanguage proficieny - does musical ability matter? Psychol. Sci. 17, 675-681. doi: 10.1111/j.14679280.2006.01765.x

Süß, H.-M., Oberauer, K., Wittmann, W. W., Wilhelm, O., and Schulze, R. (2002). Working-memory capacity explains reasoning ability-and a little bit more. Intelligence 30, 261-288. doi: 10.1016/S0160-2896 (01)00100-3

Tincoff, R., Hauser, M., Tsao, F., Spaepen, G., Ramus, F., and Mehler, J. (2005). The role of speech rhythm in language discrimination: further tests with a non-human primate. Dev. Sci. 8, 26-35. doi: 10.1111/j.1467-7687.2005.00390.x

Topbas, S. (2006). A Turkish perspective on communication disorders.
Logoped. Phoniatr. Vocol. 31, 76-88. doi: 10.1080/14015430500342384

Trofimovich, P., and Baker, W. (2006). Learning second language suprasegmentals: effect of 12 experience on prosody and fluency characteristics of L2 speech. Stud. Second Lang. Acquis. 28, 1-30. doi: 10.1017/S0272263106060013

Unsworth, N., and Engle, R. W. (2007). On the division of short-term and working memory: an examination of simple and complex span and their relation to higher order abilities. Psychol. Bull. 133, 1038-1066. doi: 10.1037/0033-2909.133.6.1038

Van Wassenhove, V., and Nagarajan, S. S. (2007). Auditory cortical plasticity in learning to discriminate modulation rate. J. Neurosci. 27, 2663-2672. doi: 10.1523/JNEUROSCI.4844-06.2007

Vuust, P., Brattico, E., Seppänen, M., Näätänen, R., and Tervaniemi, M. (2012). Practiced musical style shapes auditory skills. Ann. N.Y. Acad. Sci. 1252, 139-146. doi: 10.1111/j.1749-6632.2011.06409.x

Vuust, P., Wallentin, M., Mouridsen, K., Østergaard, L., and Roepstorff, A. (2011). Tapping polyrhythms in music activates language areas. Neurosci. Lett. 494, 211-216. doi: 10.1016/j.neulet.2011.03.015

Wallentin, M., Nielsen, A. H., FriisOlivarius, M., Vuust, C., and Vuust, P. (2010). The Musical Ear Test, a new reliable test for measuring musical competence. Learn. Individ. Differ. 20, 188-196. doi: 10.1016/j.lindif.2010.02.004

Warner, N., and Arai, T. (2001). Japanese Mora-Timing: a review. Phonetica 58, 1-25. doi: 10.1159/ 000028486

Wartenburger, I., Heekeren, H. R., Abutalebi, J., Cappa, S., Villringer, A., and Perani, D. (2003). Early setting of grammatical processing in the bilingual brain. Neuron 37, 159-170. doi: 10.1016/S0896-6273 (02)01150-9

Weber-Fox, C. M., and Neville, H. J. (1996). Maturational constraints on functional specializations for language processing: ERP and behavioral evidence in bilingual speakers. J. Cogn. Neurosci. 8, 231-256. doi: 10.1162/jocn.1996.8. 3.231

Wenk, B. J., and Wioland, F. (1982). Is French really syllable-timed? J. Phon. 10, 193-216.

Yang, H., Yang, S., Ceci, S. J., and Wang, Q. (2005). "Effects of bilinguals' controlled-attention on working memory and recognition," in ISB4: Proceedings of the 4th International Symposium on Bilingualism, eds J. Cohen, K. T. McAlister, K. Rolstad, and J. MacSwan (Somerville, MA: Cascadilla Press), 2401-2404.

Conflict of Interest Statement: The authors declare that the research was conducted in the absence of any commercial or financial relationships that could be construed as a potential conflict of interest.

Received: 21 May 2013; accepted: 20 August 2013; published online: 20 September 2013.

Citation: Roncaglia-Denissen MP, Schmidt-Kassow M, Heine A, Vuust $P$ and Kotz SA (2013) Enhanced musical rhythmic perception in Turkish early and late learners of German. Front. Psychol. 4:645. doi: 10.3389/fpsyg.2013.00645

This article was submitted to Cognitive Science, a section of the journal Frontiers in Psychology.

Copyright (c) 2013 Roncaglia-Denissen, Schmidt-Kassow, Heine, Vuust and Kotz. This is an open-access article distributed under the terms of the Creative Commons Attribution License (CC BY). The use, distribution or reproduction in other forums is permitted, provided the original author(s) or licensor are credited and that the original publication in this journal is cited, in accordance with accepted academic practice. No use, distribution or reproduction is permitted which does not comply with these terms. 